\title{
Vickers Hardness and Positron Annihilation Study of Eurofer97 and ODS Eurofer
}

\author{
I. BARTOŠOVÁ ${ }^{a, *}$, J. Č́̇̌̌̌K ${ }^{b}$, F. LUKÁČ ${ }^{b}$ AND V. SlugeÑ ${ }^{a}$ \\ ${ }^{a}$ Institute of Nuclear and Physical Engineering, Slovak University of Technology \\ Ilkovičova 3, 81219 Bratislava, Slovak Republic \\ ${ }^{b}$ Department of Low-temperature Physics, Charles University in Prague \\ V Holešovičkách 2, 18000 Prague 8, Czech Republic
}

\begin{abstract}
This paper describes investigations of Eurofer97 and oxide dispersion strengthened version of this steel, in as received state and after annealing. Vickers hardness test was performed on the as received specimens and after annealing at various temperatures to obtain information about development of the strength of studied materials. After identifying the temperature region where significant changes of the strength take place we applied positron annihilation spectroscopy to probe the microstructural changes in ferritic/martensitic steels. An observation of phase transformation was observed in both steels at various temperatures indicating different behaviour of the base material and its strengthened version. All applied methods proved the importance of strengthening by oxides to improve properties of steels.
\end{abstract}

DOI: 10.12693 /APhysPolA.125.702

PACS: $28.52 . \mathrm{Fa}$

\section{Introduction}

Oxide dispersion strengthened ferritic/martensitic (ODS F/M) steels are promising materials for high temperature applications. Hardening due to oxide dispersion in steels is discussed in detail for decades. It has been studied through various computational models and some theoretical models have been already proposed but are based on simplified microstructures [1]. Experimental studies have shown that the complexity of microstructure in steels further complicates the understanding of the hardening due to oxide dispersion. The analysis of the interaction phenomena has led to the development of a number of dislocation models, which describe the mechanical properties as a function of particle size and density [2] as in the well-known dispersed barrier hardening model [3].

In this study we focus on the $\mathrm{F} / \mathrm{M}$ steel Eurofer, the European candidate material for the future fusion reactor and for the strengthening we consider oxide of yttrium $\left(\mathrm{Y}_{2} \mathrm{O}_{3}\right)$. The oxides of yttrium and complex yttrium titanium oxides reinforce the material by forming more or less stable obstacles to dislocations, and by promoting grain refinement by pinning of grain boundaries. It appears that part of the yttrium titanium oxide particles dissolve at temperatures above $600^{\circ} \mathrm{C}$ while pure yttria particles are stable at least to $1000^{\circ} \mathrm{C}$ in steels.

The aims of this study are the following: (1) Examine hardness of the base Eurofer and the ODS version and investigate the behaviour of steels at different annealing temperatures and the changes in strength. (2) Assess

*corresponding author; e-mail: iveta.bartosova6@gmail.com defects in microstructure by coincidence Doppler broadening (CDB) and positron annihilation lifetime spectroscopy (PALS) at chosen annealing temperatures.

\section{Experimental details}

Chemical composition of studied material is given in Table. The ODS version of Eurofer contains in addition of $0.3 \%$ of $\mathrm{Y}_{2} \mathrm{O}_{3}$ particles.

TABLE

Chemical composition of Eurofer and ODS Eurofer [4].

\begin{tabular}{c|c|c|c|c|c|c|c|c|c|c|c|c}
\hline wt\% & $\mathrm{Cr}$ & $\mathrm{W}$ & $\mathrm{Mn}$ & $\mathrm{Ta}$ & $\mathrm{V}$ & $\mathrm{S}$ & $\mathrm{Si}$ & $\mathrm{N}$ & $\mathrm{C}$ & $\mathrm{Co}$ & $\mathrm{P}$ & $\mathrm{Y}_{2} \mathrm{O}_{3}$ \\
\hline
\end{tabular}

\begin{tabular}{l|l|l|l|l|l|l|l|l|l|l|l|l|l}
\hline Eurofer & 9.25 & 1.1 & 0.4 & 0.07 & 0.2 & 0.005 & 0.04 & 0.06 & 0.105 & 0.006 & 0.005 & -
\end{tabular}

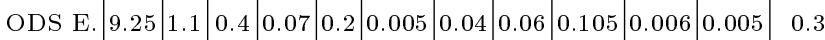

A ${ }^{22} \mathrm{Na}_{2} \mathrm{CO}_{3}$ with activity of $1 \mathrm{MBq}$ deposited on a $2 \mu \mathrm{m}$ thick Mylar foil was used as a positron source for CDB and PALS studies. A digital positron lifetime spectrometer [5] with excellent time resolution of $145 \mathrm{ps}$ $\left(\right.$ FHWM ${ }^{22} \mathrm{Na}$ ) was employed for PALS studies. At least $10^{7}$ positron annihilation events were collected in each positron lifetime spectrum. The source contribution determined using a well annealed Fe reference sample consists of two components with lifetimes of $368 \mathrm{ps}$ and $1.5 \mathrm{~ns}$ and intensities of $7 \%$ and $1 \%$ which come from positrons annihilated in the source spot and the covering foil, respectively. The source contribution is circumstantial, depending on the mechanical realization of the construction, used foil, and solution. The choice of reference sample is also important, since it estimates the contribution of the source. The intensity of source contribution depends on the atomic number of the reference sample [6]. The CDB investigations were carried out using a digital spectrometer [7] equipped with two HPGe detectors and having the resolution of $0.9 \mathrm{keV}$.

A hardness tester Struers Duramin 300 was employed for HV measurements using a load of $100 \mathrm{~g}$ applied for 
$10 \mathrm{~s}$. It was checked that different loads result in almost the same $\mathrm{HV}$ values. Each measurement was repeated at least ten times to improve precision of measurement and to estimate statistical uncertainty of the hardness values.

To study the temperature dependence of $\mathrm{HV}$ the samples were annealed at various temperatures in the range of $400-900{ }^{\circ} \mathrm{C}$. Each annealing step took $50 \mathrm{~min}$ and was finished by quenching into water at room temperature. Oxide layer which was formed during annealing at elevated temperatures was removed by chemical etching in $10 \%$ Nital solution.

\section{Results and discussion}

Figure 1 presents $\mathrm{HV}$ as a function of the annealing temperature. Eurofer steel exhibits approximately constant $\mathrm{HV}$ up to $575^{\circ} \mathrm{C}$.

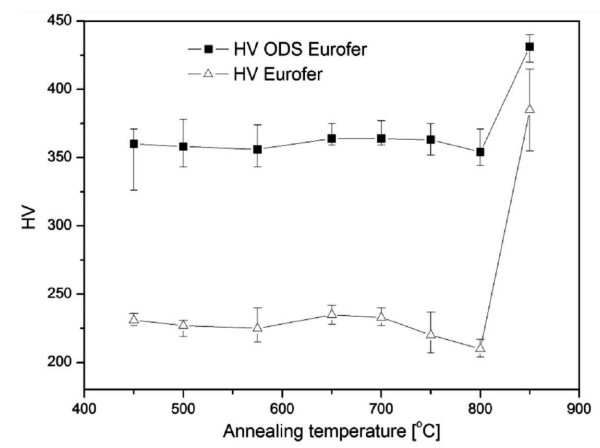

Fig. 1. HV as a function of annealing temperature for Eurofer and ODS Eurofer. Solid lines connecting the data points are intended as a guide of eye only.

A slight uprise can be noticed in the temperature range $575-650^{\circ} \mathrm{C}$ which corresponds to the diffusion of alloying elements that leads to formation of secondary precipitates. This can be understood by decomposition of supersaturated solid solution due to limited solubility of carbon. The solubility of carbon at $600^{\circ} \mathrm{C}$ is lower than at $760{ }^{\circ} \mathrm{C}$ which is the tempering temperature of ferrite. Hence, when normalized and tempered steel is treated at $600^{\circ} \mathrm{C}$, carbon further precipitates in the form of carbides. Driving force for this process is reduction of the carbon concentration dissolved in ferrite in order to adapt to the lower solubility limit. As a consequence the volume fraction of precipitates at $600{ }^{\circ} \mathrm{C}$ will be higher than at $760^{\circ} \mathrm{C}$. After exceeding $700^{\circ} \mathrm{C}$, a significant decrease of hardness occurs and $\mathrm{HV}$ reaches minimum at $800^{\circ} \mathrm{C}$. This softening could be due to coarsening of laths and precipitates resulting in the conversion of tempered martensite into coarse grained ferrite. However above $800^{\circ} \mathrm{C}$ the hardness rapidly increases. This behaviour can be explained by assuming that annealing at a temperature of $800^{\circ} \mathrm{C}$ and subsequent cooling is sufficient to induce a martensitic phase transition resulting in the microstructure of quenched martensite, with thin laths and a high density of dislocations [8].
ODS Eurofer exhibits remarkably higher hardness than the Eurofer base material due to strengthening by $\mathrm{Y}_{2} \mathrm{O}_{3}$ particles. However, the temperature dependence of $\mathrm{HV}$ for the ODS Eurofer correlates well with that of its base material. The ODS Eurofer exhibits a typical morphology of tempered martensite [8]. Similarly to the Eurofer base material $\mathrm{HV}$ of the sample heat treated above $800^{\circ} \mathrm{C}$ increases also in the ODS Eurofer, but its increase is less pronounced because of higher initial hardness of the ODS Eurofer.

The CDB ratio curves (related to well annealed pure $\mathrm{Fe}$ ) for the as-cast steels are plotted in Fig. 2. The CDB curves are enhanced at low momenta $\left(p<5 \times 10^{-3} m_{0} c\right)$ and lowered at high momenta $\left(p>10 \times 10^{-3} m_{0} c\right)$ due to positron trapping at defects. This is more pronounced in the ODS Eurofer which indicates higher concentration of defects in the sample. The CDB ratio curve for the Eurofer is rather flat in the high momentum range $\left(p>10 \times 10^{-3} m_{0} c\right)$ testifying that positrons are annihilated by $\mathrm{Fe}$ electrons. On the other hand, the high momentum part of the CDB curve for the ODS Eurofer is not flat, which indicates that some fraction of positrons is annihilated in the vicinity of $\mathrm{Y}_{2} \mathrm{O}_{3}$ particles. The CDB ratio curve measured on pure $\mathrm{Y}(99.9 \%)$ and plotted in Fig. 2 exhibits a broad valley centred at $p \approx 15 \times 10^{-3} m_{0} c$ followed by a wide peak at $p \approx 28 \times 10^{-3} m_{0} c$. The shape of the CDB ratio curve for the ODS Eurofer is similar to that for pure $\mathrm{Y}$ which gives a clear evidence that a remarkable fraction of positrons in the ODS Eurofer is annihilated by yttrium electrons. The solid line in Fig. 2 shows the CDB curve for pure Y rescaled so that it corresponds to $40 \%$ fraction of positrons annihilated by yttrium electrons. Obviously the rescaled curve is in a reasonable agreement with experimental points of the ODS Eurofer in the high momentum range $p>10 \times 10^{-3} m_{0} c$. Thus, the fraction of positrons annihilated by yttrium electrons is roughly $40 \%$. Since this value is much higher than the concentration of $\mathrm{Y}$ in the ODS Eurofer one can conclude that positrons are trapped at defects with environment enriched by $\mathrm{Y}$. Such defects are most probably open volume misfit defects at the interfaces between $\mathrm{Y}_{2} \mathrm{O}_{3}$ particles and the matrix.

The CDB ratio curves for the Eurofer and the ODS Eurofer samples annealed to various temperatures are plotted in Fig. 3a and b, respectively. The ratio curves highlight the changes in the high momentum part of the momentum distribution of annihilating electron-positron pairs. Changes in the low momentum region corresponding to annihilations by valence electrons can be better visualised using difference curves, i.e. Doppler broadened profile of a well defined reference sample (here well annealed Fe) is subtracted from the measured profile (both profiles are normalized to the same area before subtraction).

The development of the difference curves with annealing temperature for the Eurofer and the ODS Eurofer is plotted in Fig. 4a and b, respectively. One can see in Fig. 4a that in the Eurofer the peak at low momenta rep- 


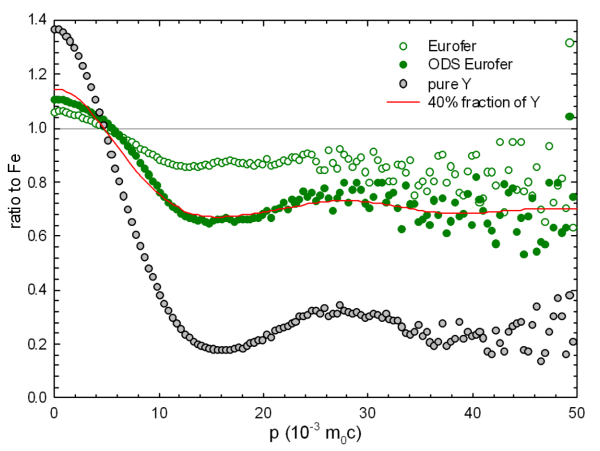

Fig. 2. CDB ratio curves (related to well annealed pure $\mathrm{Fe}$ ) for as-cast Eurofer and ODS Eurofer. The CDB ratio curve for pure $\mathrm{Y}(99.9 \%)$ is plotted in the figure as well. Solid line shows a $40 \%$ contribution of positrons annihilated by yttrium electrons.

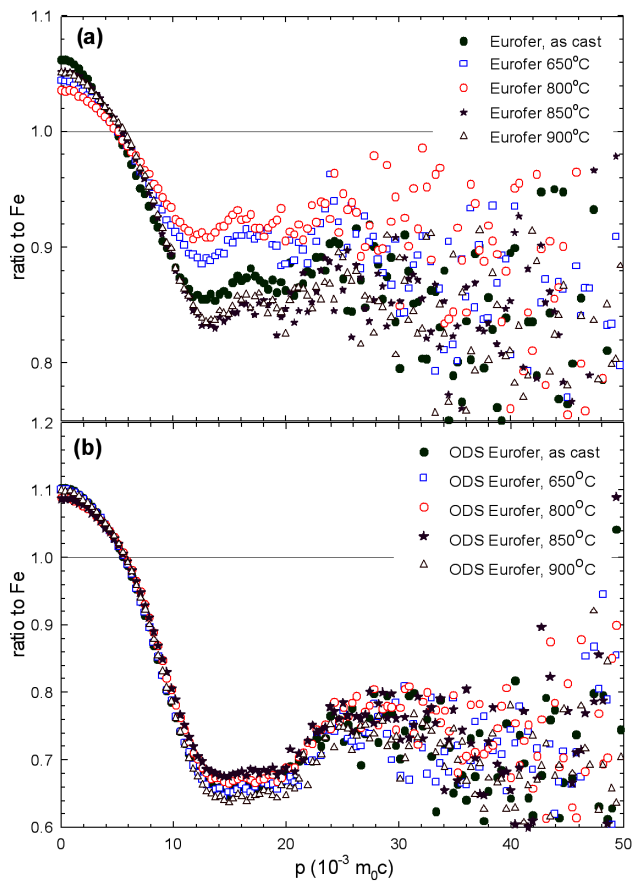

Fig. 3. CDB ratio curves (related to well annealed pure Fe) for Eurofer (a) and ODS Eurofer (b) in the as-cast state and after annealing at various temperatures.

resenting a contribution of positrons annihilated by low momentum valence electrons gradually decreases with annealing temperature up to $800^{\circ} \mathrm{C}$ suggesting recovery of dislocations during annealing of the sample. However at $850^{\circ} \mathrm{C}$ the contribution of positrons annihilating with valence electrons rised again indicating that new defects were formed. Figure $4 \mathrm{~b}$ shows that the low momentum part of the momentum distribution for the ODS Eurofer remains almost unchanged up to $650{ }^{\circ} \mathrm{C}$ and above this temperature it decreases due to recovery of dislocations. However annealing at $900{ }^{\circ} \mathrm{C}$ increased the contribution of positrons annihilated by valence electrons again. Hence, the development of the low momentum part of the momentum distribution is similar to the Eurofer base material but shifted to higher temperatures. Hence the ODS Eurofer exhibits higher temperature stability of microstructure than the Eurofer base material most probably due to pinning effect of $\mathrm{Y}_{2} \mathrm{O}_{3}$ particles.
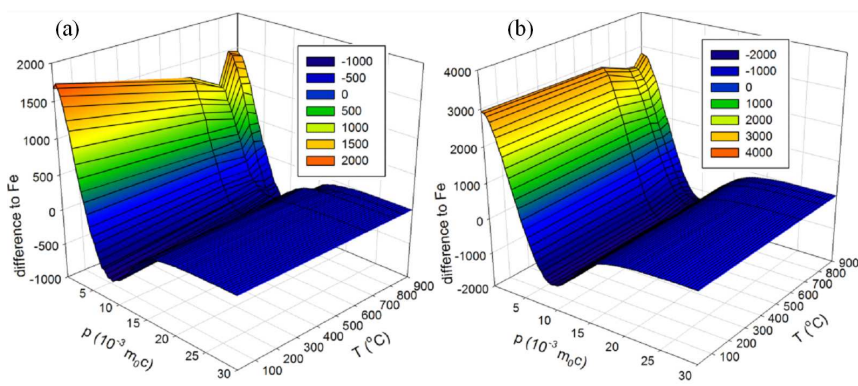

Fig. 4. The development of difference CDB curves (related to well annealed pure $\mathrm{Fe}$ ) with annealing temperature (a) Eurofer and (b) ODS Eurofer.

The development of the high momentum part of the momentum distribution for the Eurofer and the ODS Eurofer is markedly different. In case of Eurofer the high momentum part gradually increases due to recovery of dislocations up to $800{ }^{\circ} \mathrm{C}$ and subsequently it decreases again (see Fig. 3a) since new defects are introduced. On the other hand, in the ODS Eurofer the changes of high momentum part are less pronounced and retain the "yttrium-like" shape with a valley at $p \approx 15 \times 10^{-3} m_{0} c$ and a broad peak at $p \approx 28 \times 10^{-3} m_{0} c$ which indicates high temperature stability of defects associated with yttria particles.

The results of PALS investigations, i.e. the lifetimes $\tau_{i}$ of the components resolved in positron lifetime spectra and their intensities $I_{i}$ are plotted in Fig. 5a and b, respectively, as a function of the annealing temperature. The positron lifetime spectrum of the Eurofer sample consists of two components: a contribution of free positrons with lifetime $\tau_{1}<100 \mathrm{ps}$ and a component with lifetime $\tau_{2} \approx 155 \mathrm{ps}$ which agrees well with the lifetimes reported for trapped positrons in defects associated with dislocations in steels [9, 10], not dislocation lines. Hence, the component with the lifetime $\tau_{2}$ can be attributed to positrons trapped at dislocations. With increasing temperature the intensity $I_{2}$ of the dislocation component decreases up to $800^{\circ} \mathrm{C}$ due to recovery of dislocations. After exceeding $800^{\circ} \mathrm{C}$ we can observe an increase of $I_{2}$ indicating that new dislocations were created in the sample. This is not only in accordance with CDB results but it also corresponds well with the $\mathrm{HV}$ tests which assessed that at $850^{\circ} \mathrm{C}$ the strength is higher because of the phase transformation to quenched martensite leading to higher density of dislocations.

The lifetime spectra of the ODS Eurofer consist of three components: free positrons with lifetime $\tau_{1}<$ $100 \mathrm{ps}$, positrons trapped at dislocations with lifetime $\tau_{2} \approx 155 \mathrm{ps}$ and a longer component with lifetime $\tau_{3} \approx 265 \mathrm{ps}$, which comes from positrons trapped at 


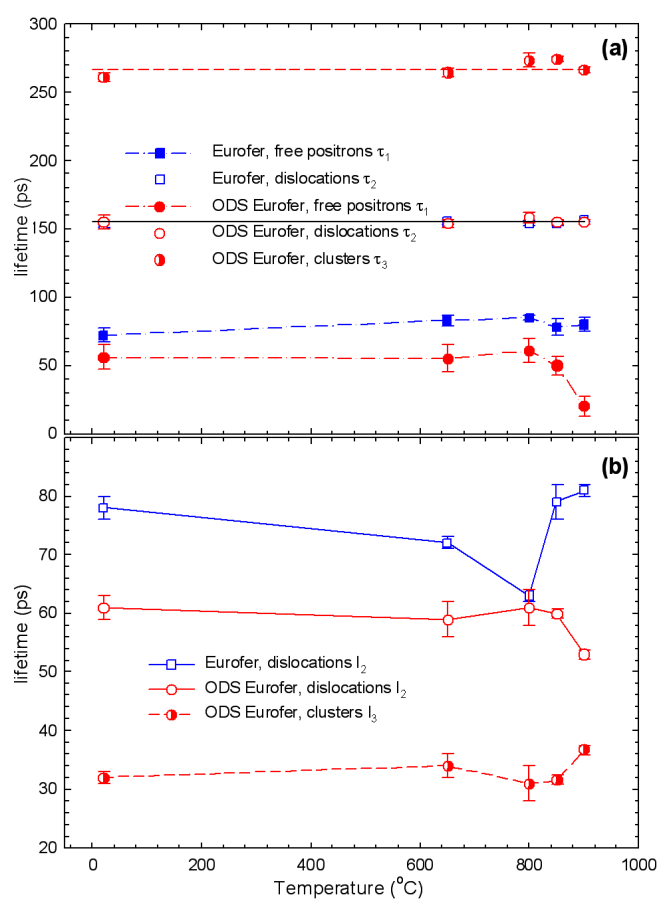

Fig. 5. Results of PALS (a) lifetimes of the positron components resolved in positron lifetime spectrum, (b) intensities $I_{2}, I_{3}$ of the components representing a contribution of positrons trapped at defects plotted as a function of the annealing temperatures.

larger defects. From comparison of the lifetime $\tau_{3}$ with theoretical calculations performed in Ref. [11] one can attribute the latter component to positrons trapped at vacancy clusters consisting of four vacancies. Since the vacancy clusters were found in the ODS Eurofer, but not in the Eurofer base material, it is plausible to assume that the vacancy clusters are associated with $\mathrm{Y}_{2} \mathrm{O}_{3}$ particles. This is supported by CDB which revealed that considerable fraction of positrons in the ODS Eurofer is trapped at defects with environment enriched by $\mathrm{Y}$ and it is also in accordance with a high thermal stability of these defects.

In contrast to the Eurofer, the intensities of defect components $I_{2}, I_{3}$ in the ODS Eurofer stay practically the same up to $850^{\circ} \mathrm{C}$ which confirms higher temperature stability of the microstructure. At $900^{\circ} \mathrm{C}$ the intensity $I_{3}$ of positrons trapped at vacancy clusters increases while the intensity $I_{2}$ of positrons trapped at dislocations decreases. It is likely that the dislocation density increases due to phase transformation to the quenched martensite, however, the concentration of vacancy clusters increases as well and since the probability of positron capture is higher for vacancy clusters than for dislocations the intensity $I_{3}$ increases at the expense of $I_{2}$. The increase of the net concentration of defects in the ODS Eurofer annealed at $900^{\circ} \mathrm{C}$ is demonstrated also by a drop of the lifetime $\tau_{1}$ of the free positron component.

\section{Conclusions}

The different behavior of ODS Eurofer steel and its base material were proven by various methods. Vickers hardness test confirmed strengthening effect of yttria particles and showed that the ODS Eurofer steel is remarkably harder than the Eurofer base material. The PALS and CDB studies revealed that the Eurofer base material and the ODS Eurofer contain a high density of dislocations. In addition, the ODS Eurofer contains vacancy clusters associated with the yttria particles. With increasing temperature the density of dislocations in the Eurofer decreases up to $800^{\circ} \mathrm{C}$. Above this temperature the dislocation density increases again due to a phase transformation to quenched martensite. In the ODS Eurofer the recovery of dislocations is shifted to higher temperatures. The phase transformation to the quenched martensite occurs in the ODS Eurofer as well but is shifted to higher temperatures. Hence, the ODS variant of Eurofer exhibits higher temperature stability of microstructure than the Eurofer base material which is obviously due to the effect of yttria particles pinning dislocations.

\section{Acknowledgments}

Financial support from the Czech Science Agency (project 107-33/12043) and the grant SVV-2013-267303 as well as from Slovak scientific agencies VEGA 1/0204/ 2013 and APVV AK48 are highly acknowledged.

\section{References}

[1] B. Derby, J.R. Walker, Scr. Metall. 22, 529 (1988).

[2] S.V. Kamat, A.D. Rollett, J.P. Hirth, Scr. Metall. Mater. 25, 27 (1991).

[3] A.K. Seeger, in: Proc. 2nd Int. Conf. on Peaceful Uses of Atomic Energy, IAEA, Vienna 1958, p. 250.

[4] A. Zeman, L. Debarberis, J. Kočík, V. Slugeň, E. Keilová, J. Nucl. Mater. 362, 259 (2007).

[5] F. Bečvář, J. Čížek, I. Procházka, J. Janotová, Nucl. Instrum. Methods Phys. Res. A 539, 372 (2005).

[6] N. Djourelov, M. Misheva, J. Phys., Condens. Matter 8, 2081 (1996).

[7] J. Čížek, M. Vlček, I. Procházka, Nucl. Instrum. Methods Phys. Res. A 623, 982 (2010).

[8] A. Ramar, R. Schäublin, J. Nucl. Mater. 432, 323 (2013).

[9] J. Čížek, I. Procházka, J. Kočík, E. Keilová, Phys. Status Solidi A 178, 651 (2000).

[10] C. Hidalgo, G. Donzález-Doncel, S. Linderoth, J.S. Juan, Phys. Rev. B 45, 7017 (1992).

[11] J. Čížek, O. Melikhova, Z. Barnovská, I. Procházka, R.K. Islamgaliev, J. Phys. Conf. Series 443, 012008 (2013). 